\title{
AUTUMN MIGRATION OF THE WOOD PIGEON, COLUMBA PALUMBUS, AT EASTERN PART OF THE POLISH BALTIC COAST
}

\author{
Justyna M. Machowina ${ }^{1}$ and Izabella Rząd ${ }^{2,3,4}$
}

\begin{abstract}
Machowina J. M., Rząd I. 2019. Autumn migration of the Wood Pigeon, Columba palumbus, at eastern part of the Polish Baltic coast. Ring 41: 27-41.

The Wood Pigeon, Columba palumbus, is a common diurnal migrant across most of the Europe. The visual observations were carried out during autumn work of the Operation Baltic ringing stations, mainly at Mierzeja Wiślana $\left(54^{\circ} 21^{\prime} \mathrm{N}, 19^{\circ} 19^{\prime} \mathrm{E}\right)$ parallely to the ringing of birds. Observations of passing birds were performed 15 minutes per every hour from sunrise to sunset. The autumn observation period was long enough to cover whole pigeons migration at the southern coast of Baltic (14 Aug. - 11 Nov.). Altogether 119,019 Wood Pigeons were observed within 20 seasons of observations. The goals of this work is (1) to describe the course of the Wood Pigeon autumn migration at the Polish Baltic coast as to numbers in long-term aspect and the seasonality of migration, (2) to propose further development in the study on wave structure of the bird passage. The main analysis of this work description of the seasonal dynamics of migration - was carried out with modified and widened method used for that kind of analysis in earlier publications. In the present paper the wave structure is described by the estimated border days between supposed waves taking under consideration different properties of the passage dynamics. Here are used three groups of parameters: (1) total numbers of birds observed daily during several years, interyear variability (as $S D$ between year number values), and the coefficient of variation $(V)$, (2) number of migration peaks that occurred in that date within years of the study (there were used two classes of peaks - High Peaks and Peaks), (3) numbers of birds passing during recognized peak days. All estimations were done independently of others and only finally summarized using common ranking scheme. Such step by step procedure make estimation more and more reliable. Very high agreement between estimations based on three groups of parameters suggests strongly that the proposed estimation procedure is effective enough.

J.M. Machowina, Izabella Rząd (corresponding author - izarzad@gmail.com).

${ }^{1}$ Department of Ecology and Environmental Protection, Institute for Research on Biodiversity, Faculty of Biology, University of Szczecin, Wąska 13, 71-415 Szczecin

2 Institute of Marine and Environmental Sciences, Faculty of Physical, Mathematical and Natural Sciences, University of Szczecin, Adama Mickiewicza 16, 70-383 Szczecin, Poland

${ }^{3}$ Operation Baltic, Bird Migration Research Station, University of Gdańsk

${ }^{4}$ Bird Migration Research Foundation, Przebendowo 3, 84-210 Choczewo
\end{abstract}

Keywords: Wood Pigeon, migration, migration waves, number dynamics, long-term data, autumn 


\section{INTRODUCTION}

The Wood Pigeon, Columba palumbus, is a common diurnal migrant across most of the Europe. As the diurnal migrant of a quite big size its passage can be easily observed by both ornithologists and common people, especially hunters. Most of information on the migration is collected in localities where the stream of migrants is concentrated by sea coast guiding lines (e.g. at Ottenby, Falsterbo, Sweden - Edelstam 1972, Ulfstrand et al. 1974) and mountain passes, as in Apenines and Pyrenees (Cavina 2015, Cavina et al. 2018). In Poland some data were collected and partly published within activity of the Operation Baltic on the Baltic coast (Manikowski 1972, Busse and Halastra 1981). The paper by Manikowski (op. cit.) covered a short period 1961-1964, while that by Busse and Halastra (op. cit.) was more general.

Cavina (2015) put an attention to the property of Wood Pigeon migration that the numbers of migrants fluctuate day by day very much. Generally, fluctuations of the passage intensity are commonly known to students of birds migration, but in this species they are really spectacular, varying from the zero individuals to several hundreds thousand pigeons per day. Cavina (op. cit.) connected this with observed changes of air pressure - the waves of migrants start soon after air pressure drops by around $10 \mathrm{hPa}$. The problem of waveness of migration was discussed by Cavina (2016) for other species of diurnal migrants (Siskin, Carduelis spinus, Chaffinch/Brambling, Fringilla sp., Starling, Sturnus vulgaris and Barnacle Goose, Branta leucopsis) in other paper. The air pressure changes seems to be direct stimulus for the starting decision of birds ready to move. From the other side, subsequent waves seems to be fixed to the "timewindows" during the season (e.g. for the Willow Warbler, Pylloscopus trochilus Piotrkowska 1995, the Blackcap, Sylvia atricapilla - Busse 1996, Kopiec 1997, Kopiec-Mokwa 1999).

The goals of this work is (1) to describe the course of the Wood Pigeon autumn migration at the Polish Baltic coast as to numbers in long-term aspect and the seasonality of migration, (2) to propose further development in the study on wave structure of the bird passage.

\section{LOCALITY AND FIELD METHODS}

Observation data on diurnal passage of birds were collected for many years (since 1961 to 1991) along the Polish Baltic coast at a few sites using the same field methods. The visual observations were carried out during work of the Operation Baltic ringing stations (Busse and Kania 1970, Busse and Halastra 1972) parallely to the ringing of birds. Observations of passing birds were performed 15 minutes per every hour from sunrise to sunset. If there was no visible birds movement during full 15-minute observation and no passage within 5 first minutes of the next, the time of that and next observations was shortened to the 5 minutes only. However, while during subsequent 5-minut observation the passage of any migrant was observed, the observation time returned to the standard 15 minutes. The stripe of observation depended on size of migrants and for such species as the Wood Pigeon was the stripe of visibility of that 
size bird by naked eyes (but identification with using binoculars) - see Busse and Kania (1970). Numbers of observed Wood Pigeons were differentiated very much between observation sites and because of a reasonably complete data were collected only at Mierzeja Wiślana $\left(54^{\circ} 21^{\prime} \mathrm{N}, 19^{\circ} 19^{\prime} \mathrm{E}\right)$ station, only these data are presented in this evaluation. Periods of work in different seasons are listed in the Table 1. Altogether 119,019 Wood Pigeons were observed within 20 seasons of observations.

Table 1

Periods of observations and numbers of observed Wood Pigeons.

$N_{\text {stand. }}-N$ within the standard period

\begin{tabular}{|c|c|c|c|}
\hline & Period of work & $N$ & $N_{\text {stand. }}$ \\
\hline 1964 & 17 Aug.-20 Oct. & 3004 & $*$ \\
\hline 1965 & 17 Aug.-25 Oct. & 13431 & 13429 \\
\hline 1966 & 17 Aug.-25 Oct. & 1427 & 1427 \\
\hline 1967 & 17 Aug.-26 Oct. & 6788 & 6786 \\
\hline 1968 & 17 Aug.-25 Oct. & 1416 & 1408 \\
\hline 1969 & 17 Aug.-25 Oct. & 4963 & 4959 \\
\hline 1970 & no data & & - \\
\hline 1971 & 20 Aug.-7 Nov. & 12521 & 12514 \\
\hline 1972 & 3 Oct.-16 Nov. & 621 & $*$ \\
\hline 1973 & 15 Aug.-11 Nov. & 8606 & 8606 \\
\hline 1974 & 15 Aug.-22 Aug. & 28 & $*$ \\
\hline 1975 & 16 Aug.-2 Nov. & 6987 & 6981 \\
\hline 1976 & no data & & - \\
\hline 1977 & no data & & - \\
\hline 1978 & no data & & - \\
\hline 1979 & no data & & - \\
\hline 1980 & 14 Aug.-2 Nov. & 3254 & 3162 \\
\hline 1981 & 14 Aug-1 Nov. & 10356 & 10348 \\
\hline 1982 & 14 Aug-1 Nov. & 8960 & 8862 \\
\hline 1983 & 14 Aug-1 Nov. & 2007 & 2000 \\
\hline 1984 & 14 Aug-1 Nov. & 2832 & 2801 \\
\hline 1985 & 14 Aug-1 Nov. & 7396 & 7390 \\
\hline 1986 & no data & & - \\
\hline 1987 & no data & & - \\
\hline 1988 & 14 Aug-1 Nov. & 5831 & 5831 \\
\hline 1989 & 15 Aug-25 Aug. & & $*$ \\
\hline 1990 & 14 Aug.-1 Nov. & 4356 & 4353 \\
\hline 1991 & 14 Aug.-9 Oct. & 14235 & $*$ \\
\hline Standard & 20 Aug.-25 Oct. & & 100857 \\
\hline
\end{tabular}

* not full length of the standard period covered by observations 


\section{METODS OF ANALYSIS}

As a first step of the analysis it was setting the common period of the season when observations were conducted during most of years (20 August - 25 October). In years 1964, 1972, 1974 and 1991 real periods of observations were shorter than the "standard period" (Table 1, Appendix). The analyses were performed only for the data included into the standard period.

Long-term population number dynamics was analysed using the linear regression of the standard period numbers of observed pigeons in years of the study.

The main analysis of this work - description of the seasonal dynamics of migration - was carried out with modified method used for that kind of analysis in earlier publications by Busse and Kopiec (Busse 1996), Kopiec (1997) and Kopiec-Mokwa (1999). For all years separately there were calculated percent values of daily numbers. They were a basis for calculation of the average daily number of migrants for all years of the study (Avg.\%), the standard deviation of the daily number values $(S D)$ and the daily variation coefficient $(V \%=S D / A v g$.) $\mathrm{x} 100)$. The studied parameters (Avg., $S D, V \%$ total values) were called "the I group of parameters". Received distributions of these parameters were tested using chi-square for their normality. The results shown that distributions are not normal ones. Following cited above literature there was set a hypothesis that the migration pattern includes several waves of migrants. Thus identification of the waves and the border days between the waves need the further analysis. The second step analysis was limited to the period 19 September -19 October, when the most intensive migration occurs.

Within every year seasonal pattern of migration the peak days were identified and labelled as "High Peaks" ( $>25 \%$ of this year number of observed birds) or "Peaks" (5-20\% of the yearly number). Number of peaks was counted for every day of the studied season (high peaks and other peaks separately). These were treated as a second source of information about periodicity of the migration (II parameter group). The third group of parameters was the average numbers of birds passing per day of the season classified as the peak days. From these additional parameters there were estimated the border days between suspected waves of migration, as well as days of the waves peaks. It must be stressed that estimations of the border days between waves as well as top days of waves were done for groups of parameters independently from others groups so detail results are independent and they can be summarized for reaching higher probability of the final estimation of the wave structure and its seasonal course.

According to all three sources of information about the passage waveness, days were ranked as: "-1" - a border wave day, “+1" - wave top day (other days were ranked as "0"). Summing up the rank values for days there was received the most probable division of the passage into migratory waves. 


\section{RESULTS}

\section{Long-term number dynamics}

Intensity of the Wood Pigeon migration at Mierzeja Wiślana in years 1964-1991 (but in years 1964, 1970,1972, 1974, 1976-1979, 1996, 1997, 1989, 1991 the data were lacking or incomplete) varied very much (Table 1, Fig. 1): with yearly average $N=$ 5951, $S D=4221$, thus $V \%=70,9$. As to compatible observation period, the lowest number of pigeons was observed in 1968 (1408 ind.) while the highest - in 1965 $(13,429)$. Generally, the number of observed pigeons had negative trend (coefficient of regression $\left.b=-78.2, S E_{b}=118.5\right)$, but because of very high variation it was not statistically significant $\left(p>0.05, F_{14}=0.43\right)$. For years 1971-1990 the local trend was stronger negative, but still above traditional $p=0.05$ of significance $\left(b=-318.2, S E_{b}\right.$ $\left.=152.4, F_{9}=4.36\right)$.

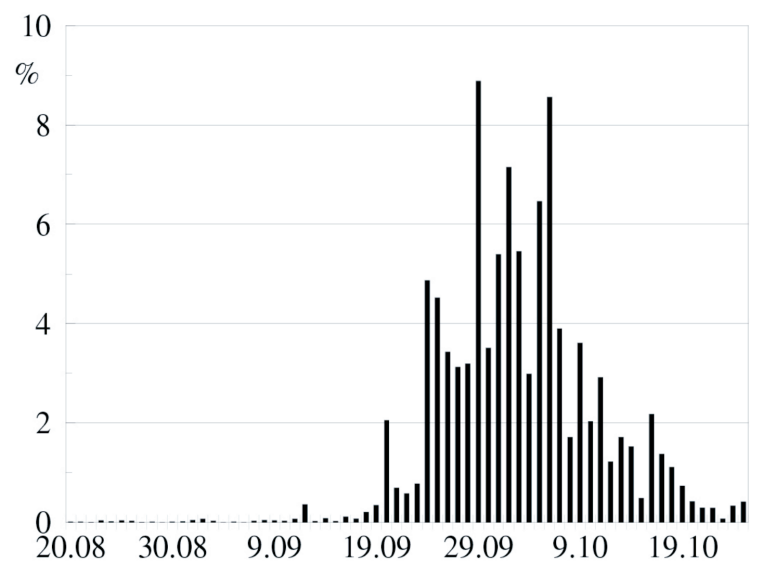

Fig. 1. Number dynamics of the Wood Pigeon migration at Mierzeja Wiślana over the years of study. Dots - yearly results, Line - dynamics smoothed by moving average.

\section{Seasonal dynamics}

The autumn observation period was long enough to cover whole pigeons migration at the southern coast of Baltic (14 Aug. - 11 Nov. - Table 1, Fig. 2). In August and first half of September pigeons on migration were not observed, while after half of October numbers were very low. The period for that analysis was set for 19 Sep. 19 Oct. In a general analysis, daily results within the standard period were expressed as percent of the that year total observed. So, they can be averaged for all years to the total pattern of the number dynamics of migration (Fig. 3). Despite there is presented averages from a number of years, the distribution is not regular and there is reasonable to suspect that the distribution deviate from the simple normal distribution, even when the daily data are smoothed (by a moving 5-days average). The daily numbers distribution $(N)$ deviates from the regular normal distribution as tested by $c h i^{2}\left(c h i^{2}=\right.$ 34.35, $d f=24, p=0.08$ ) at the level close to traditional level of statistical signifi- 
cance. This agrees with similar studies on other species (Piotrkowska 1995, Busse 1996, Kopiec 1997). The daily variation $(S D)$ between yearly results has the same properties of the distribution: $c h i^{2}=55.35, p$ 0.001, and the coefficient of variation $V$ too: $c h i^{2}=$ 349.3, $p<0.001$. Distributions of the number and the standard deviation are positively strongly, significantly correlated: $r=0.96, p<0.001\left(F_{29}=340.9\right)$, while for a pair number $(N)$ - coefficient of variation $(V)$ the correlation is significantly negative: $r=-0.41$, $p<0.05\left(F_{29}=5.86\right)$ and for the pair $S D-V$ it is not significantly negative: $r=-0.23$, $p<0.05\left(F_{29}=1.62\right)$. The negative correlation between number and variation means that in days of lower intensity of the passage (thus days of suspected borders between the migration waves) the variation is higher, that means that migration is more chaotic, less synchronised.

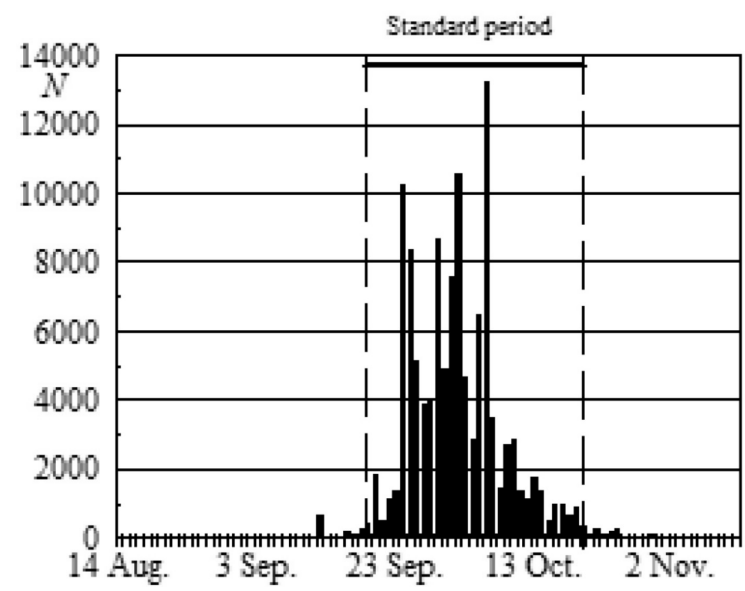

Fig. 2. Total seasonal number dynamics of the Wood Pigeon migration at Mierzeja Wiślana. Vertical broken lines limit the standard period of observations.

According to the number raw data pattern and the smoothed curve there can be estimated in which days the borders between migration waves are situated (Fig. 4). This pattern, based on this group of the data parameters, will be the object of testing for its reality using additional information from the raw data.

The next step of the analysis is directed to a timing of observation the local peaks of migration within the yearly intensity of migration patterns. For every year days of seasonal migration were ranked as described in the Methods of analysis chapter (p. 29): High Peaks and Peaks. These peaks were distributed unevenly along the analysed period (Fig. 5). In the same time these distributions were significantly correlated: $r=0.49$, $p<0.01\left(F_{29}=9.16\right)$. They brought some new information to the general analysis and they are treated here as a second group of the parameters.

In further analysis, not only classification of the days as High Peaks-Peaks is taken under consideration, but additionally the frequences of birds passing the observation site in these days (Fig. 6). Distribution of frequences in High Peaks - Peaks was significantly positively correlated: $r=0.57, p<0.01\left(F_{29}=13.96\right)$, thus these parameters could be used as the next group of parameters used for estimation of the waveness of the bird migration. 

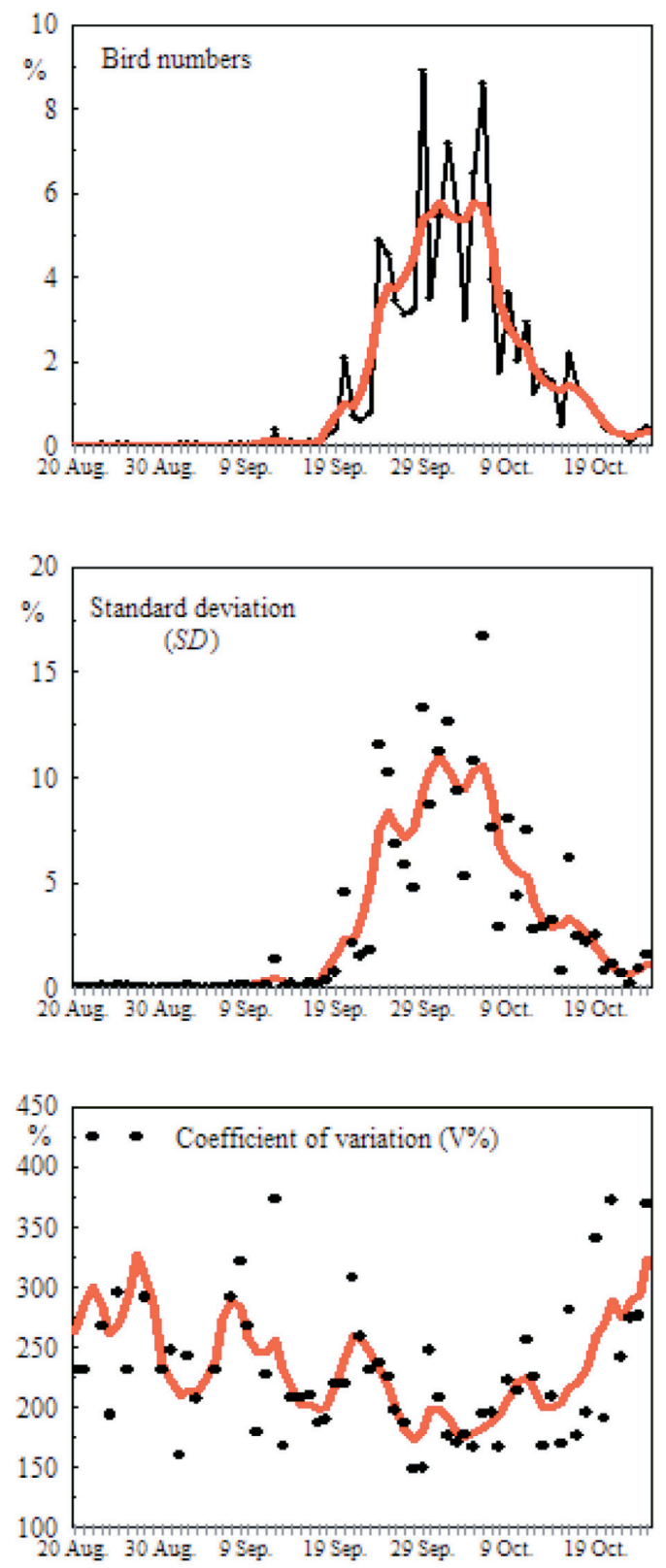

Fig. 3. Total seasonal dynamics of migration within the standard period, expressed as an average percent share of daily numbers in the yearly totals. Parameters: Numbers, Standard Deviation and Coefficient of Variation. Dots - daily averages, Line - dynamics smoothed by moving average. 


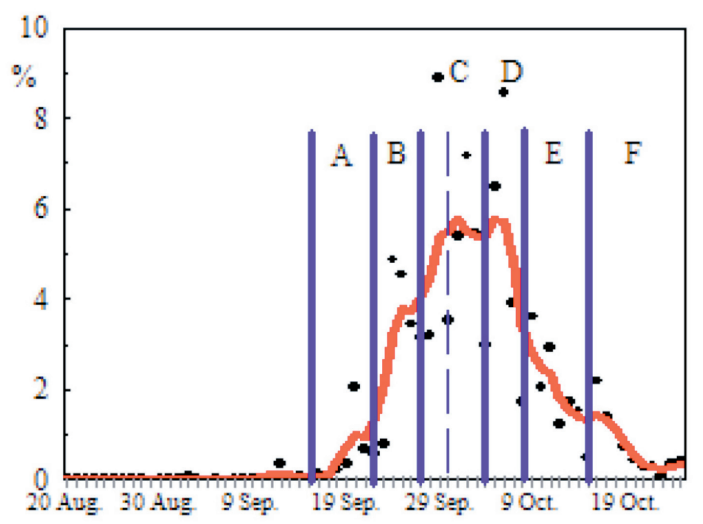

Fig. 4. Estimated waves of migration within the standard period as a hypothese from the total daily migration numbers, expressed as at Fig. 3. Dots - daily averages, Line - dynamics smoothed by moving average. Vertical lines - estimated wave border days.
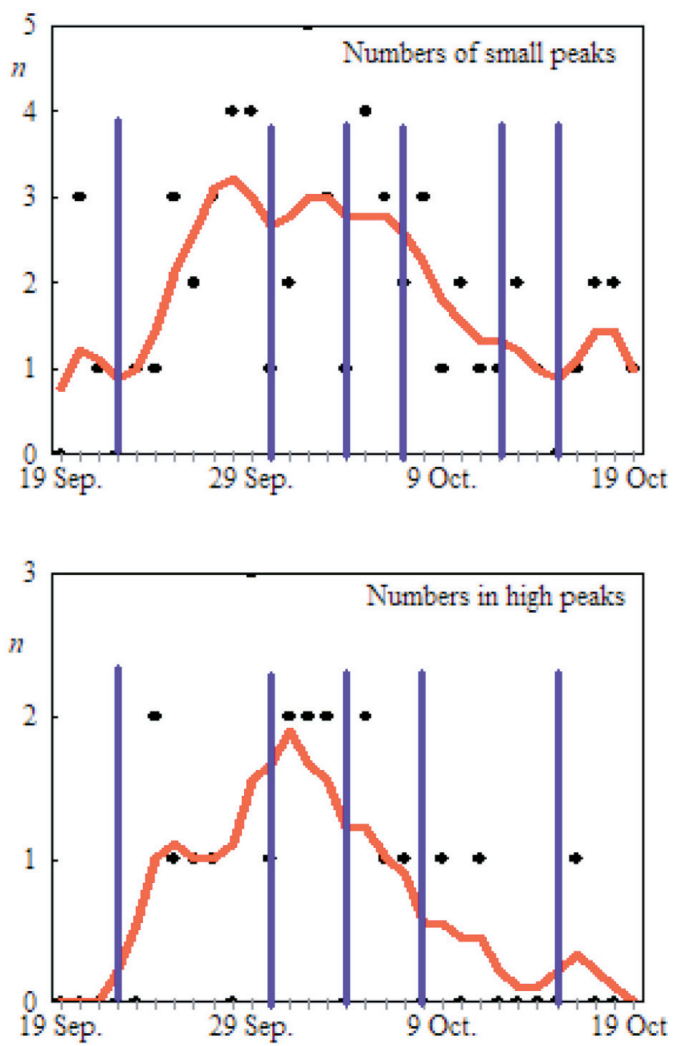

Fig. 5. Distributions of Peaks (days $5-20 \%$ of the yearly migration) and High Peaks (> 25\%) within the standard period. Dots - daily averages, Line - dynamics smoothed by moving average. Vertical lines - estimated wave border days. 

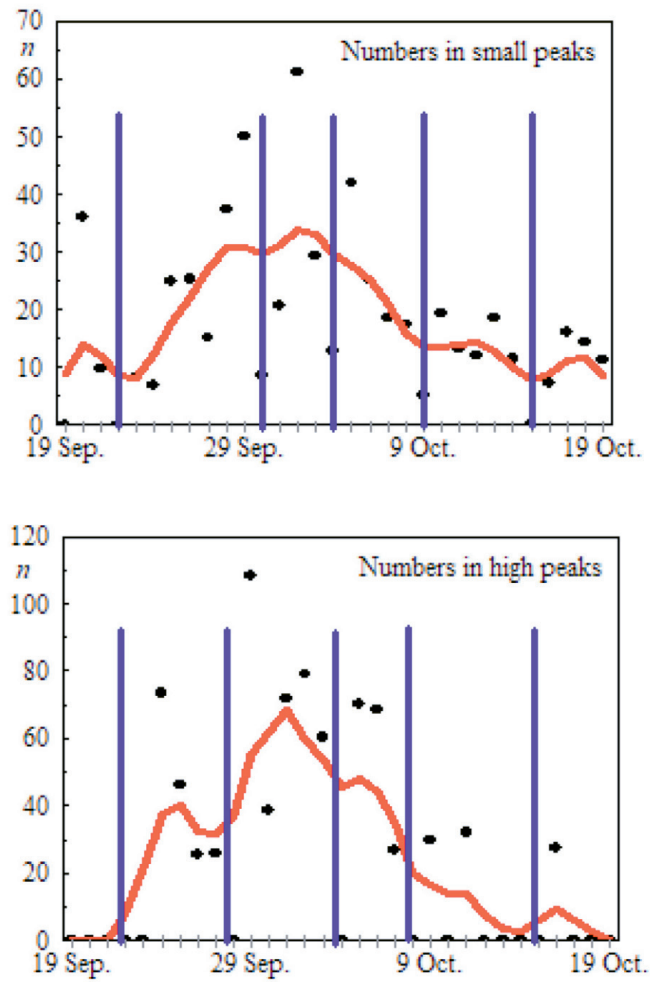

Fig. 6. Distributions of number of migrants in Peaks (days 5-20\% of the yearly migration) and High Peaks ( $>25 \%$ ) within the standard period. Dots - daily averages, Line - dynamics smoothed by moving average. Vertical lines - estimated wave border days

Finally, all days of the studied period were ranked as to their status in the process of estimation of the migration wave structure: “-1" - a border wave day, "+1" - wave top day (other days were ranked as " 0 "). Figure 7 presents results of the procedure.

Table 2

Final estimation of the border dates between waves

\begin{tabular}{|c|c|c|c|c|c|c|c|c|c|c|c|}
\hline & \multicolumn{11}{|c|}{ Wave: } \\
\hline Parameters & $\mathbf{A}$ & $\mathrm{A} / \mathrm{B}$ & B & $\mathrm{B} / \mathrm{C}$ & C & $\mathrm{C} / \mathrm{D}$ & D & $\mathrm{D} / \mathrm{E}$ & $\mathbf{E}$ & $\mathrm{E} / \mathrm{F}$ & $\mathbf{F}$ \\
\hline Bird numbers & & $\begin{array}{c}22 \\
\text { Sep. }\end{array}$ & & $\begin{array}{c}28 \\
\text { Sep. }\end{array}$ & $\begin{array}{l}(30 \\
\text { Sep.) }\end{array}$ & 4 Oct. & & 9 Oct. & & $\begin{array}{c}15 \\
\text { Oct. }\end{array}$ & \\
\hline Peaks frequency & & $\begin{array}{c}22 \\
\text { Sep. }\end{array}$ & & $\begin{array}{c}28 \\
\text { Sep. }\end{array}$ & $\begin{array}{l}(30 \\
\text { Sep.) }\end{array}$ & 4 Oct. & & $\begin{array}{c}10 \\
\text { Oct. }\end{array}$ & & $\begin{array}{c}15 \\
\text { Oct. }\end{array}$ & \\
\hline Peaks values & & $\begin{array}{c}22 \\
\text { Sep. }\end{array}$ & & $\begin{array}{l}28 \\
\text { Sep. }\end{array}$ & $\begin{array}{l}30 \\
\text { Sep. }\end{array}$ & 4 Oct. & & 9 Oct. & & $\begin{array}{l}15 \\
\text { Oct. }\end{array}$ & \\
\hline Border dates & & $\begin{array}{r}22 \\
\text { Sep. }\end{array}$ & & $\begin{array}{c}28 \\
\text { Sep. }\end{array}$ & & 4 Oct. & & $\begin{array}{l}9 / 10 \\
\text { Oct. }\end{array}$ & & $\begin{array}{c}15 \\
\text { Oct. }\end{array}$ & \\
\hline $\begin{array}{l}\text { Length of the } \\
\text { wave (days) }\end{array}$ & (4) & & 6 & & $(2+4) ?$ & & 4 & & 6 & & $(5-6)$ \\
\hline
\end{tabular}



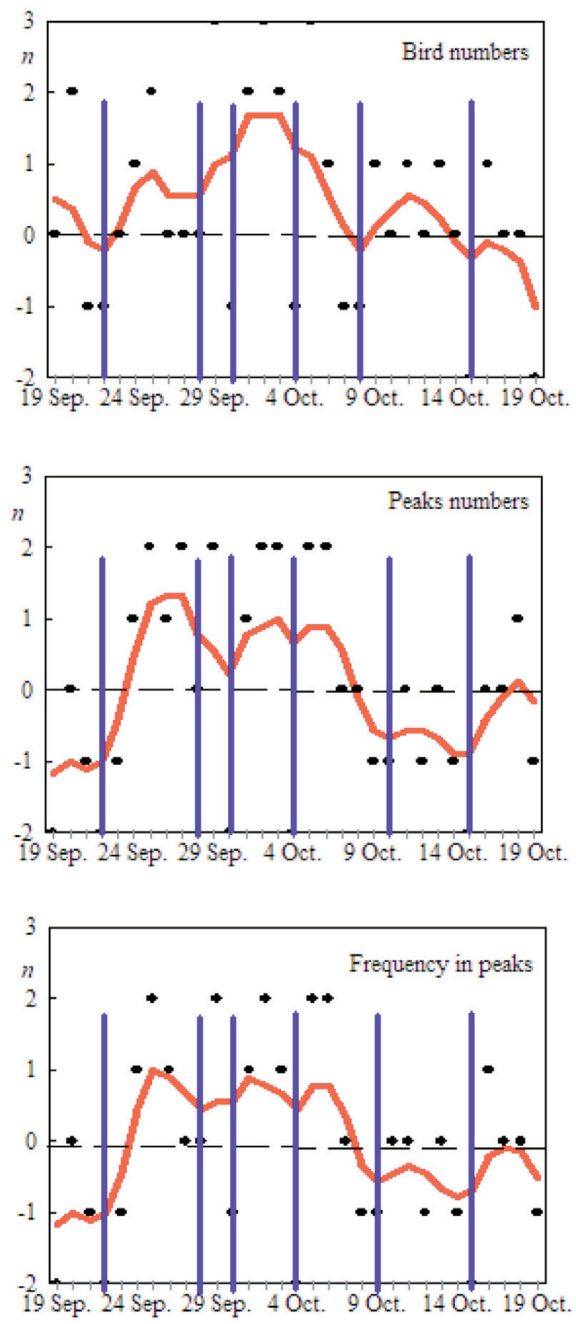

Fig. 7. Estimated wave border days according to rankings of days in three groups of parameters: Numbers of migrants (Fig. 3), Numbers of yearly peaks (Fig. 5) and Numbers of migrants in the peak days (Fig. 6). Dots - sums of daily ranks, Line - dynamics smoothed by moving average. Vertical lines - estimated wave border days.

It must be stressed that the estimation procedure was carried out independently for all three discussed groups of parameters describeing the migration pattern. Thus, it would be reasonable to compare these partial estimations. The correlation of distribution of border days between supposed waves of migration estimated in the first group of parameters (total numbers) and those estimated on the basis of the second group (numbers of peaks) is statistically positive: $r=0.73, p<0.001\left(F_{29}=33.09\right)$; between the first group and the third one (numbers in peak days) as well as between second and third group are significantly positive too: respectively $-r=0.80, p<0.001$ $\left(F_{29}=51.56\right)$ and $r=0.91, p<0.001\left(F_{29}=139.7\right)$. Thus, the result wave pattern given in the Table 2 and illustrated at Figure 8 could to be claimed as very well grounded. 


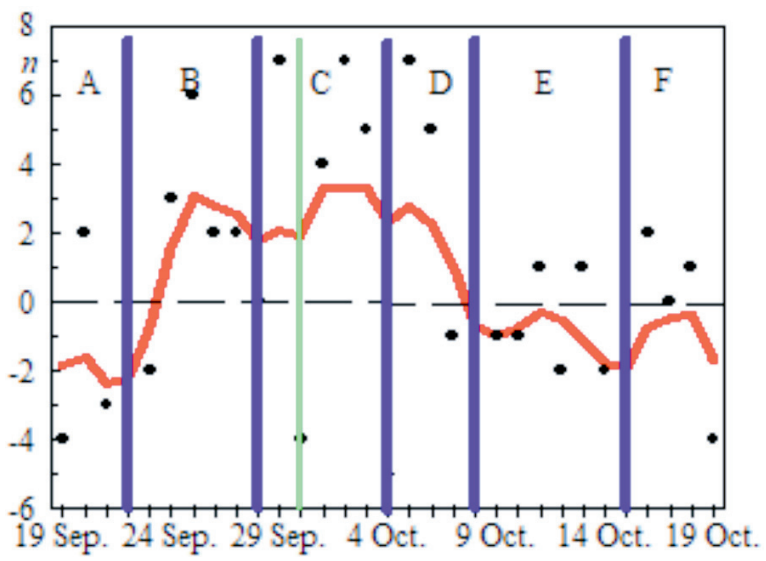

Fig. 8. Summarized ranks from all parameters used for estimation of the wave border days. Dots sums of daily ranks, Line - dynamics smoothed by moving average. Vertical lines estimated wave border days.

\section{DISCUSSION}

Further studies on the seasonal structure of the passage of bird migrants at the study sites needs more and more information about course of seasonal migration of birds in many sites along the migration routes. In the case of the Wood Pigeon migration in Poland there were published generalized information by Tomiałojć and Stawarczyk (2003) and a few field study data from the the early work of the Operation Baltic (Manikowski 1972, Busse and Halastra 1981), as well as from observations 2008-2011 performed on the Vistula Spit (Bela et al. 2011, 2012, Kilon et al. 2013, Kośmicki et al. 2015) at the site localized around $20 \mathrm{~km}$ away of the Mierzeja Wiślana station. Some information was published recently about the data collected in the southern part of Poland (Bobrek et al. 2017). Additionally it should be mentioned that a lot of dispersed observations were collected at many sites all over Poland performed as an obligatory monitorings of the planned wind-farm localities. These data are still not published and even difficult to reach. The Mierzeja Wiślana station data presented here is the most complete sample that describe the course the Wood Pigeon migration in Poland. It could be helpful in any evaluation of the Wood Pigeon migration over Europe.

The additional goal of the paper was to develop the more convincing estimation procedure of description the wave structure of the bird migration. Since introductory publication presenting estimation method of the wave structure of the passage (Busse 1996) some development was proposed - from first in papers by Kopiec-Mokwa (1999) till Cavina et al. 2018. In the present paper the wave structure is described by the estimated border days between supposed waves taking under consideration different properties of the passage dynamics. Here are used three groups of parameters: (1) total numbers of birds observed daily during several years, inter-year variability (as $S D$ between year number values), and the coefficient of variation $(V),(2)$ number of migra- 
tion peaks that occurred in that date within years of the study (there were used two classes of peaks - High Peaks and Peaks), (3) numbers of birds passing during recognized peak days. All estimations were done independently of others and only finally summarized using common ranking scheme. Such step by step procedure make estimation more and more reliable. Very high agreement between estimations based on three groups of parameters (Table 2) suggests strongly that the proposed estimation procedure is effective enough.

\section{ACKNOWLEDGEMENTS}

The authors are grateful very much to Prof. Przemysław Busse for encourage the work, sharing the raw data for this evaluation, make suggestions and extensive discussion of subsequent versions of the paper, as well as for a final editorial work.

\section{REFERENCES}

Bela G., Janczyszyn A., Kośmicki A. 2011. Migration of Falconiformes, Columbiformes and Corvidae on the Vistula Spit in autumn 2008. Ptaki Pomorza 2: 75-92.

Bela G., Janczyszyn A., Kośmicki A. 2012. Migration of Falconiformes, Columbiformes and Corvidae on the Vistula Spit in autumn 2009. Ptaki Pomorza 3: 135-138.

Bobrek R., Wilk T., Pępkowska-Król A. 2017. Migration of the Woodpigeon Columba palumbus in the Polish Carpathians - migration parameters and birds' selectivity for meteorological variables. Ornis Polonica 58: 160-177.

Busse P. 1996. Modelling of the seasonal dynamics of bird migration. Ring 18, 1-2: 97-119.

Busse P. and Halastra G. 1981. The autumn migration of birds on the Polish Baltic sea coast. Acta orn. 18, 3: 167-290.

Busse P. and Kania W. 1970. Operation Baltic 1961-1967. Methods of work. Acta orn. 7: 231-268.

Cavina E. 2015. Decision making of autumn migrations of woodpigeons (Columba palumbus) in Europe: analysis of the abiotic factors and atmospheric pressure changes. www. scienceheresy. com/ornithologyheresy/Cavina 2015

Cavina E. 2016. The para-tympanic organ of Vitali: the challenge of bird sensory physiology. www. scienceheresy.com/ornithologyheresy/Cavina 2016

Cavina E., Bucchi R. and Busse P. 2018. The general pattern of seasonal dynamics of the autumn migration of the Wood Pigeon Columba palumbus in Italy. Ring 40: 3-18.

Edelstam C. 1972. The Visible Migration of Birds at Ottenby, Sweden. Var Fagelv. Suppl. 7

Kilon D., Bela G., Kośmicki A., Janczyszyn A., Niemczyk A., Zientek P. 2013. Migration of Falconiformes, Columbiformes and Corvidae on the Vistula Spit in autumn 2010. Ptaki Pomorza 4: 155-158.

Kopiec K. 1997. Seasonal pattern of the Blackcap (Sylvia atricapilla) autumn migration at the Polish Baltic coast. Ring 19, 1-2:41-58.

Kopiec-Mokwa K. 1999. Dates of migration waves - a coincidence or an effect of biologically based mechanism? Improvement of the method of analysing the seasonal migration dynamics. Ring 21, 2: 131-144.

Kośmicki A., Janczyszyn A., Niemczyk A., Kilon D., Bela G., Zientek P. 2015. Migration of raptors, Aciteriformes, falcons Falconiformes, doves Columbiformes and crows Corvidae on the Vistula Spit in autumn 2011. Ptaki Pomorza 5: 140-144.

Manikowski S. 1972. Analysis of autumn migration of Wood Pigeon (Columba palumbus) on the Polish Baltic coast in the years 1961-1964. Not. Orn. 13, 1-2: 1-10. 
Piotrkowska L. 1995. [Analysis and comparison of the dynamics of autumn migration of Willow Warbler (Phylloscopus trochilus) at Bukowo, Hel and Vistula Spit.] Diploma work at University of Gdańsk, Poland. (in Polish)

Tomiałojć L. and Stawarczyk T. 2003. The avifauna of Poland. Distribution, numbers and trends. vol. 2. PTTP "pro Natura", Wrocław

Ulfstrand S., Roos G., Alerstam T. and Österdahl L. 1974. Visible Bird Migration at Falsterbo, Sweden. Var Fagelv. Suppl. 8. 


\section{Appendix}

Daily raw observation data in the years of observations.

Periods of active observations shown by arrows.

Note differentiated number scale $(y)$, depending on yearly numbers.
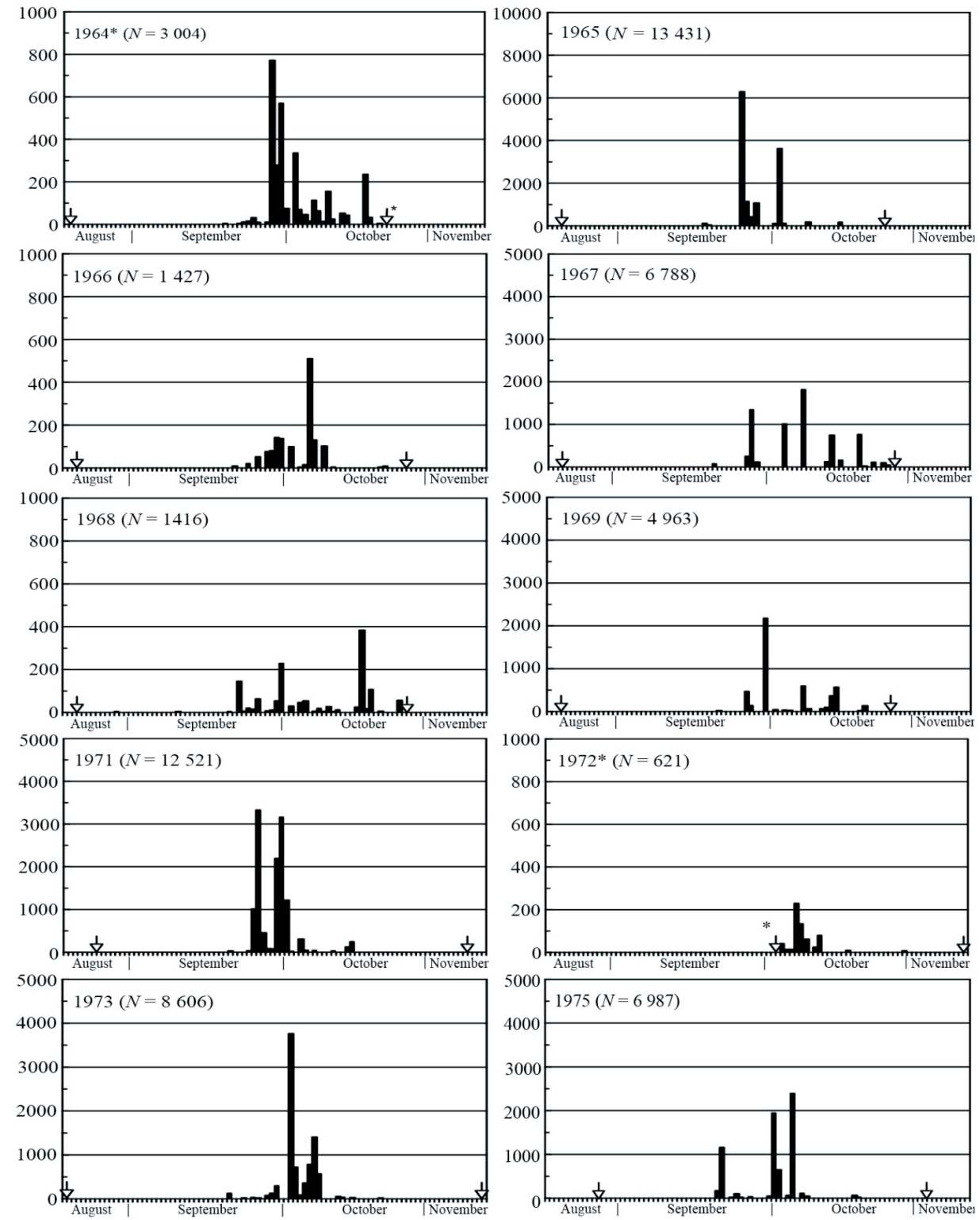

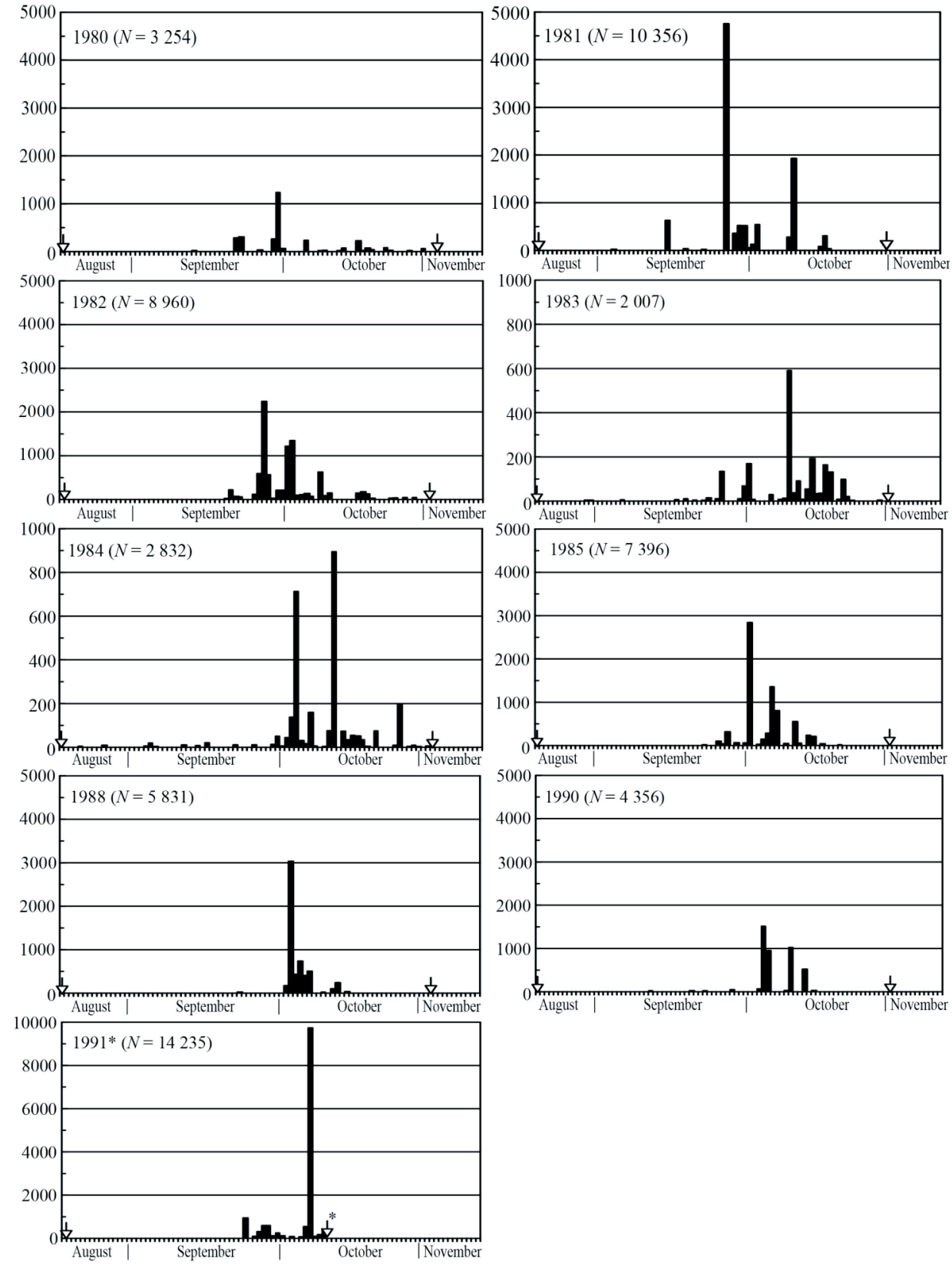

* - not full standard period covered. 